\title{
Reply to the letter to the editor: bimonthly injections of ranibizumab for age-related macular degeneration
}

\author{
Tomoko Sawada $\cdot$ Masahito Ohji
}

Received: 18 November 2014 / Accepted: 20 November 2014 / Published online: 6 December 2014

(C) Springer-Verlag Berlin Heidelberg 2014

Dear Editor,

We thank Dr Abdullah Ilhan for the interest and comments on our manuscript entitled "Bimonthly injections of ranibizumab for age-related macular degeneration" [1].

In our study, the visual acuity (VA) improved consistently except between month 3 and month 4 , but the central retinal subfield thickness (CRST) showed fluctuation through the observation period [1]. An increase in CRST usually occurs from the macular edema or serous retinal detachment, as in the representative case we showed in Figure 3, and means deterioration of exudative age-related macular degeneration (AMD) [1]. Therefore, an increase in CRST with deterioration of exudative AMD necessitates additional injections of antivascular endothelial growth factor to improve or keep VA.

The time estrangement between VA change and CRST change may depend on the paper that the recurrences of $\mathrm{CNV}$ determined by spectral-domain optical coherence tomography were preceded by a loss of intraocular VEGF suppression and usually followed by loss of VA in the further course [2]. Therefore, correlation analyses between VA change and CRST change would not be useful.

\section{References}

1. Sawada T, Kakinoki M, Wang X, Kawamura H, Saishin Y, Ohji M (2014) Bimonthly injections of ranibizumab for age-related macular degeneration. Graefes Arch Clin Exp Ophthalmol 252:1545-1551

2. Muether PS, Hermann MM, Viebahn U, Kirchhof B, Fauser S (2012) Vascular endothelial growth factor in patients with exudative agerelated macular degeneration treated with ranibizumab. Ophthalmology 119:2082-2086
T. Sawada $(\bowtie) \cdot$ M. Ohji

Department of Ophthalmology, Shiga University of Medical Science,

Seta Tsukinowacho, Otsu, Shiga 520-2192, Japan

e-mail: tsawada@belle.shiga-med.ac.jp 